\title{
CORRELATION OF NEAREST NEIGHBOUR DISTANCE AND BONDING PARAMETERS OF EXAFS OF SOME Mn AND Co SYSTEMS
}

\author{
V.K. Singh and A.R. Chetal \\ Department of Applied Physics, Indian School of Mines \\ Dhanbad 826 004, India
}

(Received May 30, 1997; revised version September 3, 1997; in final form November 13, 1997)

\begin{abstract}
Analysing the EXAFS of several Mn and Co systems, the absorbing atom phase shift $\alpha$ and backscattering amplitude phase shift $\beta$ are evaluated. It is shown that the parameters $\alpha$ and $\beta$ vary linearly with the nearest neighbour distance, $R$, except in the systems $\mathrm{CoCl}_{2} \cdot 6 \mathrm{H}_{2} \mathrm{O}, \mathrm{MnSO}_{4} \cdot \mathrm{H}_{2} \mathrm{O}$ and $\mathrm{MnF}_{2}$. The nearest neighbour distance, $R$, in the complicated systems like smaltite and braunite minerals was also determined. The values are close to the crystallographic values.
\end{abstract}

PACS numbers: 78.70.Dm

\section{Introduction}

Extended X-ray absorption fine structure (EXAFS), which refers to oscillations of the X-ray absorption coefficient on the high energy side of the absorption edge, has proved to be an extremely useful technique for the structure studies. Sayer et al. [1] suggested the following expression for EXAFS function $\chi(k)$ :

$$
\chi(k)=-(1 / k) \sum_{j=1}^{\text {shells }} A_{j} \sin \phi_{j}(k),
$$

where the sum is over all shells $j$ and the term $\phi_{j}(k)=2 k R_{j}+\delta_{j}(k)$ [2] is the phase shift of the photoelectron in the scattering process. Here wave function $A_{j}$ is an amplitude function containing the coordination number, the scattering amplitude term, the Debye-Waller factor and the inelastic loss term and $k$ photoelectron wave vector. In the $\phi_{j}(k)$ term the phase change $2 k R_{j}$ is due to the travel of the photoelectron from the absorbing atom to the neighbouring atom and back and an additional phase shift $\delta_{j}(k)$ includes the term $-2 \alpha_{j} k+2 \beta_{j}$ in which $2 \alpha_{j} k$ is an absorbing atom phase shift and $2 \beta_{j}$ is a backscattering amplitude phase shift. Here 
we assumed $\alpha_{j}$ to be linear in $k$ over the EXAFS energy range [2]. The coefficient $\alpha_{j}$ can be also defined as bonding parameter.

In the present paper, we have studied the relation between parameters of phase shift $\alpha_{1}$ and $\beta_{1}$ and the crystallographic nearest neighbour distance $R_{1}$ of some $\mathrm{Mn}$ and Co systems [3].

\section{Experimental}

A Cauchois type transmission X-ray spectrograph with diameter $40 \mathrm{~cm}$ was used to record $K$-absorption spectra of systems under study. X-ray radiation was obtained from tungsten tube operated at $13 \mathrm{kV}$ and $10 \mathrm{~mA}$. In order to vary the $\mathrm{X}$-ray radiation energy, the mica crystal with $\overline{2} 01$ planes was used. Absorbing samples were prepared by spreading uniformly fine powder of the compounds between two cellophane tapes fixed on an aluminium frame. Microphotometer traces of the intensity of spectra were recorded from the photographic film using MD100 (Carl Zeiss, IRS) microphotometer. The error in the measurement of the positions of the maxima and minima in absorption spectra was of the order of $\pm 1 \mathrm{eV}$.

\section{Results and discussion}

We are interpreting our results on graphical technique proposed by Lytle et al. [2]. The analysis depends on the argument of the sine in Eq. (1). They assumed in their theory a $\delta_{j}(k)$ being a linear function of $k$ as given below

$$
\delta_{j}(k)=-2 \alpha_{j} k+2 \beta_{j},
$$

where $\alpha_{j}$ and $\beta_{j}$ are constants.

Substituting into the argument of the sine of Eq. (1) and rearranging for the first coordination shell, it is convenient to define $n$ by

$$
(n+1 / 2) \pi=2 k\left(R_{1}-\alpha_{1}\right)+2 \beta_{1},
$$

where $n=0,2,4 \ldots$ for maxima, and $n=1,3,5 \ldots$ for minima.

The value of $k$ is obtained from the following equation:

$k=(0.263 E)^{1 / 2}$,

where $E$ is the energy of the peaks in the EXAFS.

By plotting $n$ versus $k$ curve for the maxima and the minima of the measured EXAFS [4-6], the value of $R_{1}-\alpha_{1}$ in Eq. (3) can be obtained from the slope of $n$ versus $k$ curve. Once $R_{1}$, the crystallographic value of the nearest neighbour distance of the above systems are substituted in the values of $R_{1}-\alpha_{1}$, the values of $\alpha_{1}$ of corresponding systems can be calculated easily. $\beta_{1}$ was determined from the intersection of the $n$ versus $k$ curve. The values so obtained using Eq. (3) are tabulated in Table I.

The graphs of the modulus of bonding parameter $\alpha_{1}$ and parameter $\beta_{1}$ in function of $R_{1}$, the nearest neighbour crystallographic distance, are shown in Fig. 1 and Fig. 2 for cobalt and manganese systems, respectively. It is evident from the graph that as the value of $R_{1}$ increases the modulus of the bonding parameter $\alpha_{1}$ also increases except in $\mathrm{CoCl}_{2} \cdot 6 \mathrm{H}_{2} \mathrm{O}, \mathrm{MnSO}_{4} \cdot \mathrm{H}_{2} \mathrm{O}$ and $\mathrm{MnF}_{2}$. The deviation may be due to the effect of other ligands associated with higher shells [2]. We also see from Fig. 1 and Fig. 2 that as $R_{1}$ increases the values of the modulus of $\beta_{1}$ also 
TABLE I

Data for bonding parameter, nearest neighbour distance and backscattering term.

\begin{tabular}{|c|c|c|c|c|}
\hline $\begin{array}{l}\text { Sl. } \\
\text { No. }\end{array}$ & $\begin{array}{l}\text { Name } \\
\text { of the } \\
\text { system }\end{array}$ & $\begin{array}{c}\text { Bonding } \\
\text { parameter } \\
\alpha_{1}\end{array}$ & $\begin{array}{c}\text { Nearest } \\
\text { neighbour } \\
\text { distance } \\
R_{1} \\
\end{array}$ & $\begin{array}{c}\text { Back- } \\
\text { scattering } \\
\text { term } \\
\beta_{1} \\
\end{array}$ \\
\hline 1 & Co-metal & -1.86 & 2.50 & -13.39 \\
\hline 2 & $\mathrm{CoS}$ & -1.51 & 2.13 & -9.57 \\
\hline 3 & $\mathrm{CoCl}_{2} \cdot 6 \mathrm{H}_{2} \mathrm{O}$ & -1.43 & $2.43^{*}$ & -11.15 \\
\hline 4 & $\mathrm{CoO}$ & -1.37 & 2.13 & -9.57 \\
\hline 5 & $\mathrm{Co}\left(\mathrm{ClO}_{4}\right) \cdot 6 \mathrm{H}_{2} \mathrm{O}$ & -1.20 & 2.10 & -8.93 \\
\hline 6 & $\mathrm{CoSo}_{4} \cdot 2 \mathrm{H}_{2} \mathrm{O}$ & -1.15 & 1.99 & -8.34 \\
\hline 7 & $\mathrm{Co}_{2} \mathrm{O}_{3}$ & -1.02 & 1.80 & -7.15 \\
\hline 8 & $\mathrm{MnS}$ & -1.55 & 2.61 & -10.99 \\
\hline 9 & Mn-metal & -1.43 & 2.60 & -9.79 \\
\hline 10 & $\mathrm{MnO}$ & -1.10 & 2.22 & -8.86 \\
\hline 11 & $\mathrm{MnCO}_{3}$ & -0.91 & 2.15 & -7.96 \\
\hline 12 & $\mathrm{MnSO}_{4} \cdot \mathrm{H}_{2} \mathrm{O}$ & -0.897 & $2.18^{*}$ & -8.02 \\
\hline 13 & $\mathrm{MnF}_{2}$ & -0.89 & $2.16^{*}$ & -7.46 \\
\hline 14 & $\mathrm{Mn}_{2} \mathrm{O}_{3}$ & -0.86 & 2.02 & -6.98 \\
\hline
\end{tabular}

${ }^{*}$ Calculated values.

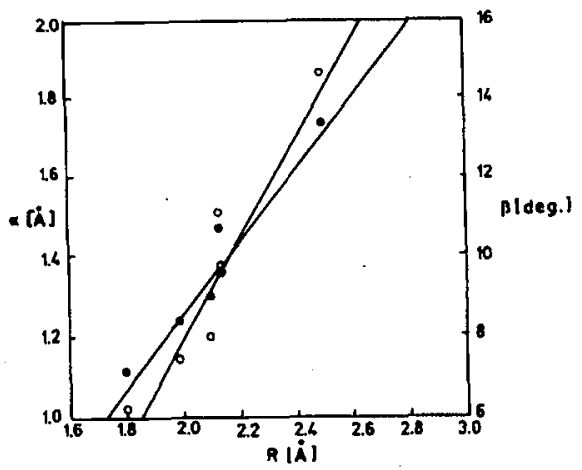

Fig. 1. $R$ vs. $\alpha$ (in $\AA$ ) and $\beta$ (in degrees) of Co system.

increase except in $\mathrm{CoCl}_{2} \cdot 6 \mathrm{H}_{2} \mathrm{O}, \mathrm{MnSO}_{4} \cdot \mathrm{H}_{2} \mathrm{O}$ and $\mathrm{MnF}_{2}$ due to the same reason mentioned above. Knowing the value of $\alpha_{1}$ and $\beta_{1}$ from EXAFS measurements of smaltite minerals ( $\left.\mathrm{CoAs}_{3}\right)$ and braunite minerals $\left(3 \mathrm{Mn}_{2} \mathrm{O}_{3} \cdot \mathrm{MnSiO}_{3}\right)$ and from Figs. 1 and 2, we determined the value of nearest neighbour distance, $R_{1}$ (given 
TABLE II

Calculated values of bonding parameter, nearest neighbour distance and backscattering term.

\begin{tabular}{c|c|c|c|c|c}
\hline \hline $\begin{array}{c}\text { Sl. } \\
\text { No. }\end{array}$ & Name of the systems & $\begin{array}{c}\text { Bonding } \\
\text { parameter } \\
\alpha_{1}\end{array}$ & $\begin{array}{c}\text { Nearest } \\
\text { neighbour } \\
\text { distance } \\
R_{1}^{*}\end{array}$ & $\begin{array}{c}\text { Back- } \\
\text { scattering } \\
\text { term } \\
\beta_{1}\end{array}$ & $\begin{array}{c}\text { Nearest } \\
\text { neighbour } \\
\text { distance } \\
R^{* *}\end{array}$ \\
\hline 1 & Smaltite minerals & -1.51 & 2.25 & -9.57 & 2.35 \\
2 & Braunite minerals & -1.02 & 2.18 & -8.38 & 2.19 \\
\hline
\end{tabular}

${ }^{*}$ Calculated values.

${ }^{* *}$ Crystallographic values.

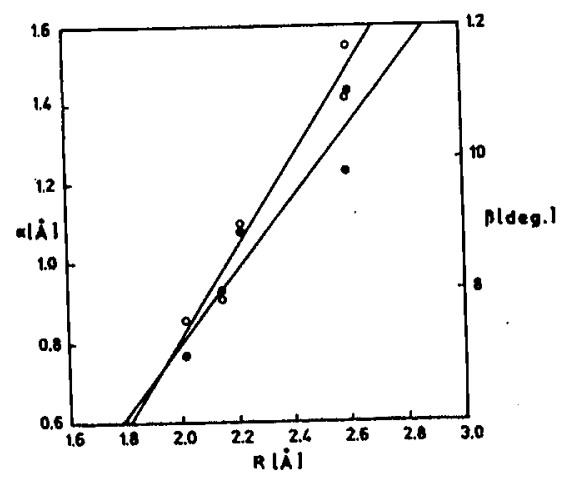

Fig. 2. $\quad R$ vs. $\alpha$ (in $\AA$ ) and $\beta$ (in degrees) of Mn system. $R$ - nearest neighbour distance, $\alpha-$ absorbing atom phase shift, $\beta-$ backscattering amplitude phase shift. $\circ R$ vs. $\alpha, \bullet R$ vs. $\beta$.

in Table II) for these minerals. The values agree fairly well with crystallographic values given in Table II.

\section{References}

[1] D.E. Sayers, E.A. Stern, F.W. Lytle, Phys. Rev. Lett. 27, 1204 (1971).

[2] F.W. Lytle, D.E. Sayers, E.A. Stern, Phys. Rev. B 11, 4825 (1975).

[3] B.J. Rao, Ph.D. thesis, Indian School of Mines, Dhanbad 1983.

[4] P. Mahto, A.R. Chetal, Phys. Rev. Lett. 58, 889 (1987).

[5] A. Murari, A.R. Chetal, Phys. Status Solidi B 183, 287 (1994).

[6] M.N. Ghatikar, Phys. Status Solidi B 135, 487 (1986). 